\title{
Repurposing Dihydroartemisinin-Piperaquine-Doxycycline as an Antimalarial Drug: A Study in Plasmodium berghei-Infected Mice
}

\author{
Udeme Owunari Georgewill ${ }^{1, *}$, Elias Adikwu ${ }^{2}$ \\ ${ }^{1}$ Department of Pharmacology, Faculty of Basic Clinical Sciences, University of Port Harcourt, Rivers State, Nigeria \\ ${ }^{2}$ Department of Pharmacology and Toxicology, Faculty of Pharmacy, Niger Delta University, Bayelsa State, Nigeria. \\ Corresponding author* \\ udgeorgewill@yahoo.com
}

Manuscript received: 06 December 2021. Revision accepted: 12 December, 2021. Published: 16 December, 2021.

\begin{abstract}
Artemisinin-based combination (ACT) therapy is the mainstay for malaria treatment. However, Plasmodium parasite with decreased susceptibility to ACT has emerged. Hence, it is imperative to discover new drugs or explore new drug combinations that can decrease Plasmodium parasite resistance. This study assessed the antiplasmodial activity of dihydroartemisinin-piperaquine- doxycycline (D-PDX) on mice infected with Plasmodium berghei. Swiss albino mice (25-30g) of both sexes inoculated with $1 \times 10^{7}$ Plasmodium berghei intraperitoneally were used. The mice were randomly grouped and orally treated with DX $(2.2 \mathrm{mg} / \mathrm{kg}), \mathrm{D}-\mathrm{P}(1.71 / 13.7 \mathrm{mg} / \mathrm{kg})$ and D-PDX daily in curative, suppressive and prophylactic studies. The negative and the positive controls were treated daily with normal saline $(0.2 \mathrm{~mL})$ and chloroquine $(\mathrm{CQ})(10 \mathrm{mg} / \mathrm{kg})$, respectively. After treatment, blood samples were assessed for percentage parasitemia, hematological and lipid parameters. The mice were observed for mean survival time. D-P, DX, and D-P-DX produced significant decreases in percentage parasitemia at $\mathrm{p}<0.05, \mathrm{p}<0.01$ and $\mathrm{p}<0.001$, respectively when compared to negative control. In the curative study, D-P, DX, and D-P-DX produced $64.9 \%, 71.1 \%$, and $93.6 \%$ parasitemia inhibitions when compared to $75.0 \%$ inhibition produced by CQ. Plasmodium berghei -induced alterations in packed cell volume, white blood cells, red blood cells, hemoglobin, high-density lipoprotein cholesterol, total cholesterol, low-density lipoprotein cholesterol, and triglyceride levels were significantly restored by DX $(\mathrm{p}<0.05)$ and D-P $(\mathrm{p}<0.01)$ and D-P-DX $(\mathrm{p}<0.001)$ when compared to the negative control. D-P-DX showed significant antiplasmodial activity against Plasmodium berghei-infected mice. It may be clinically useful for the treatment of malaria.
\end{abstract}

Keywords; artemisinins; doxycycline; malaria; repurposing; resistance.

\section{INTRODUCTION}

World Health Organization (WHO) estimates that nearly half of the world's population lived in malaria endemic areas (WHO, 2016). Malaria, a Plasmodium parasite infection is one of the greatest health challenges in tropical regions, despite the availability of antimalarial drugs, mosquito repellents and insecticide-treated nets. Malaria chemotherapy remains a major focus of research, and new molecules are being discovered prior to the emergence of drug-resistant strains of Plasmodium parasite (Gaillard et al., 2015). The use of antimalarial drugs is faced with the development of resistance from Plasmodium falciparum in primarily endemic areas. Other challenges include financial costs, contraindications, and clinical tolerance (Gaillard et al., 2015).

Doxycycline (DX), a broad-spectrum bacteriostatic agent is synthetically obtained from naturally occurring tetracyclines produced by Streptomyces sp. (McEvoy et al., 2008). It acts by binding to several proteins in the $30 \mathrm{~S}$ ribosomal small subunit and to different ribonucleic acids in the $16 \mathrm{~S}$ ribosomal RNA. In addition to its antimicrobial activity, it is a partially efficacious prophylactic drug with activity against liver stage of Plasmodium and blood schizontocides. It is highly effective for the prevention of malaria. The U.S. Food and Drug Administration (FDA) approved the use of DX for prophylaxis of Plasmodium falciparum in short-term travelers to areas with chloroquine or pyrimethaminesulfadoxine-resistant strains (Tan et al., 2011). DX can be used for the treatment of malaria in children less than 8 years old and non-pregnant adults in combination with quinine sulfate for uncomplicated and chloroquineresistant Plasmodium falciparum. It is also used with primaquine and quinine sulfate for uncomplicated chloroquine-resistant Plasmodium vivax and with parenteral quinidine for severe malaria (Griffith et al., 2007).

Artemisinin derivatives are highly potent with fast acting antiplasmodial activity. However, due to short half-life, and Plasmodium parasite resistance to artemisinin derivatives and older antimalarial drugs, artemisinin derivatives are often combined with partner drugs with longer half-life for fast clearance of malaria parasites (Nosten, 2007). This led to the development of 
artemisinin-based combination therapies (ACTs), which have become the mainstay for the treatment of malaria especially in malaria endemic regions (Basco et al., 2017). However, Plasmodium parasites with decreased susceptibility to ACTs' have emerged due to both decreased susceptibility to artemisinins and partner drugs (Leang et al., 2013; Sanders et al., 2014). Also, dihydroartemisinin-piperaquine (D-P), one of the currently used ACTs, which is efficacious against malaria (Tayler et al., 2020) and is being considered for the prevention of malaria in pregnancy (Kakuru et al., 2016; Desai et al., 2016) has experienced Plasmodium resistance in malaria endemic regions. Plasmodium resistance was attributed to decreased susceptibility to both piperaquine and dihyroartemisinin (Amaratunga et al., 2016; Amato et al., 2017). Hence this study aimed to evaluate if the antiplasmodial effect of D-P can be augmented by DX in mice infected with Plasmodium berghei.

\section{MATERIALS AND METHODS}

\section{Animals, Drugs and Parasites}

Swiss albino mice of both sexes (25-30 g) used for this study were sourced from the animal husbandry of the Department of Pharmacology, Faculty of Basic Clinical Sciences, University of Port Harcourt, Rivers State. The mice were housed in cages at temperature $20^{\circ} \mathrm{C}$ with cycles of $12 \mathrm{~h}$ light $/ 12 \mathrm{~h}$ darkness. The mice were acclimated for 2 weeks and fed with food pellets and given water ad libitum. CQ was manufactured by Alben Healthcare Ind Ltd, D-P was manufactured by Bliss GVS Pharma Ltd India whereas DX was manufactured by Ranbaxy Laboratories Ltd, India. Doses were selected based on previous studies: CQ $(10 \mathrm{mg} / \mathrm{kg})$ (Somsak et al., 2018), DX (2.2 mg/kg) (Gaillard et al., 2015) and D-P (1.71/13.7 mg/kg) (Yavo et al., 2011). CQ-sensitive Plasmodium berghei (P. berghei) (NK65) was used. $P$. berghei was obtained from Nigerian Institute of Medical Research, Yaba, Lagos. Mice used were inoculated intraperitoneally (i.p.) with $0.2 \mathrm{~mL}$ of infected red blood cells (RBCs) containing $P$. berghei $\left(1 \times 10^{7}\right)$ obtained from the donor mice.

\section{Evaluation of Antiplasmodial Activity \\ - Evaluation of curative activity}

Curative activity was performed as reported by Ryley and Peters (1970). Twenty-five Swiss albino mice were inoculated i.p with blood containing $1 \times 10^{7}$. P. berghei and grouped into 5 of 5 mice each. The first two groups, AI (Negative control) and A2 (Positive control) were orally treated with normal saline $(0.2 \mathrm{~mL})$ and CQ $(10 \mathrm{mg} / \mathrm{kg})$ daily for 4 days, respectively. Groups A3-A5 were orally treated with DX $(2.2 \mathrm{mg} / \mathrm{kg})$, D-P $(1.71 / 13.7$ $\mathrm{mg} / \mathrm{kg}$ ) and D-P-DX daily for 4 days, respectively. On day 5 , tail blood samples were collected from the mice; thin blood films were produced on slides and stained with Giemsa stain and viewed with the aid of a microscope. Evaluations for percentage parasitemia and inhibitions were performed using the formula below.

$$
\begin{gathered}
\% \text { Parasitemia }=\frac{\text { Number of parasitized red blood cells }(\mathrm{RBCs}) \times 100}{\text { Total } \text { number of RBCs count }} \\
\% \text { Inhibition }=\frac{(\% \text { Parasitemia of negative control }-\% \text { Parasitemia of treated group }) \times 100}{\% \text { Parasitemia of negative control }}
\end{gathered}
$$

\section{- Evaluation of prophylactic activity}

Prophylactic test was performed using an established method described by Peters (1965). Twenty-five Swiss albino mice were assigned to 5 groups of 5 mice each. Group BI served as the negative control and group B2 served as the positive control and were orally treated with normal saline $(0.2 \mathrm{ml})$ and CQ $(10 \mathrm{mg} / \mathrm{kg})$ daily for 4 days, respectively. Groups B3-B5 were orally treated with DX $(2.2 \mathrm{mg} / \mathrm{kg})$, D-P $(1.71 / 13.7 \mathrm{mg} / \mathrm{kg})$ and D-PDX daily for 4 days, respectively. On day 5 , the mice were inoculated i.p with $0.2 \mathrm{~mL}$ of infected blood containing $1 \times 10^{7} P$. berghei. After, 3 days, tail blood samples were collected and percentage parasitemia and inhibitions were calculated using the formula above.

\section{- Evaluation of suppressive activity}

Suppressive test was carried out as described by Knight and Peters (1980). Twenty-five mice were selected and inoculated i.p with blood containing $1 \times 10^{7} P$. berghei. After $3 \mathrm{~h}$, the mice were randomized into 5 groups of 5 mice each. The first two groups, CI (Negative control) and C2 (Positive control) were orally treated with normal saline $(0.2 \mathrm{~mL})$ and CQ $(10 \mathrm{mg} / \mathrm{kg})$ daily for 4 days, respectively. Groups C3-C5 were orally treated with DX $(2.2 \mathrm{mg} / \mathrm{kg})$, D-P $(1.71 / 13.7 \mathrm{mg} / \mathrm{kg})$ and D-PDX daily for 4 days, respectively. On day 5 , tail blood samples were collected and evaluated for percentage parasitemia and inhibitions using the formula above.

\section{Evaluation of Biochemical Parameters}

Blood samples were collected from the mice used for the curative test and evaluated for white blood cells (WBCs), hemoglobin (HB), packed cell volume (PCV), red blood cells (RBCs), triglyceride (TG), total cholesterol (CHOL), and high-density lipoprotein cholesterol (HDL-C) using an auto analyzer. 


\section{Statistical Analysis}

Results as mean \pm S EM (standard error of mean). Data was analyzed using one-way analysis of variance (ANOVA) and Tukey's test. Differences between means were considered significant at $p<0.05,0.01$ and 0.001, respectively.

\section{RESULTS}

\section{Curative Activity}

Treatment with DX, D-P, and D-P-DX significantly decreased percentage parasitemia levels at $\mathrm{p}<0.05$, $\mathrm{p}<0.01$ and $\mathrm{p}<0.001$, respectively when compared to the negative control (Table 1). The observed parasitemia inhibitions produced by DX, D-P, and D-P-DX and CQ were $64.9 \%, 71.1 \%, 93.6 \%$, and $75.0 \%$, respectively (Table 2). MST was significantly prolonged in mice treated with DX, D-P, and D-P-DX at $\mathrm{p}<0.05, \mathrm{p}<0.01$, and $\mathrm{p}<0.001$, respectively when compared to the negative control (Table 1).

\section{Suppressive Activity}

Percentage parasitemia levels were significantly decreased in mice treated with DX, D-P and D-P-DX at $\mathrm{p}<0.05, \quad \mathrm{p}<0.01$, and $\mathrm{p}<0.001$, respectively when compared to the negative control (Table 2). Treatment with DX, D-P and D-P-DX produced 66.5\%, $75.0 \%$, and 95.1\% parasitemia inhibitions, respectively whereas CQ produced $81.9 \%$ parasitemia inhibition (Table 2). Significant prolongation of MST in DX, D-P and D-PDX-treated mice occurred at $\mathrm{p}<0.05, \mathrm{p}<0.01$ and $\mathrm{p}<0.001$, respectively when compared to negative control (Table 2).

\section{Prophylactic Activity}

The prophylactic test showed significant decreases in percentage parasitemia levels in mice treated with DX $(\mathrm{p}<0.05)$, D-P $(\mathrm{p}<0.01)$ and D-P-DX $(\mathrm{p}<0.001)$ when compared to the negative control (Table 3). The percentage parasitemia inhibitions produced by DX, D-P and D-P-DX were $65.1 \%, 86.8 \%$, and $98.9 \%$, respectively while CQ produced an inhibition of $85.7 \%$ (Table 3). MST was prolonged in DX, D-P, and D-PDX-treated mice. This occurred at $\mathrm{p}<0.05, \mathrm{p}<0.01$, and $\mathrm{p}<0.001$, respectively when compared to the negative control (Table 3).

\section{Determination of Mean Survival Time}

The mice in the control and the treated groups were observed for mortality and expressed in days. Mortality represented as mean survival time (MST) was calculated using the formula bellow.

$$
M S T=\frac{\text { Sum of survival time of all mice in a group (days) }}{\text { Total number of mice in that group }}
$$

\section{Hematological and Lipid Parameters}

In $P$. berghei-infected mice, TG, CHOL, LDL-C and WBCs increased whereas HB, PCV, RBCs and HDL-C decreased significantly $(p<0.001)$ when compared to the normal control (Tables 4 and 5). On the other hand, TG, CHOL, LDL-C WBCs levels were decreased whereas $\mathrm{HB}, \mathrm{PCV}, \mathrm{RBC}$ and HDL-C levels were increased significantly in mice treated with DX, D-P, and D-P-DX at $\mathrm{p}<0.05, \mathrm{p}<0.01$ and $\mathrm{p}<0.001$, respectively when compared to the negative control (Tables 4 and 5).

Table 1. Curative antiplasmodial effect of dihydroartemisinin-piperaquine-doxycycline on mice infected with Plasmodium berghei.

\begin{tabular}{llll}
\hline Treatment & \% Parasitemia & \% Inhibition & MST (Days) \\
\hline PC & $35.10 \pm 3.00$ & 0.0 & $9.22 \pm 0.18$ \\
CQ & $8.78 \pm 1.54^{\mathrm{a}}$ & 75.0 & $27.62 \pm 2.39^{\mathrm{a}}$. \\
DX & $12.30 \pm 1.27^{\mathrm{b}}$ & 64.9 & $14.15 \pm 1.66^{\mathrm{b}}$ \\
D-P & $10.11 \pm 1.11^{\mathrm{a}}$ & 71.1 & $25.83 \pm 2.65^{\mathrm{a}}$ \\
D-P-DX & $2.25 \pm 0.15^{\mathrm{c}}$ & 93.6 & $36.96 \pm 3.48^{\mathrm{c}}$ \\
\hline
\end{tabular}

Data presented as \pm SEM, $n=5$, PC: Negative control, CQ: Chloroquine, DX: Doxycycline, D-P: Dihydroartemisinin-piperaquine, MST: Mean survival time. ${ }^{\mathrm{a}} \mathrm{p}<0.01,{ }^{\mathrm{b}} \mathrm{p}<0.05,{ }^{\mathrm{c}} \mathrm{p}<0.001$ Significant different when compared to PC, SEM: Standard error mean.

Table 2. Suppressive antiplasmodial effect of dihydroartemisinin-piperaquine-doxycycline on mice infected with Plasmodium berghei.

\begin{tabular}{llll}
\hline Treatment & \% Parasitemia & \% Inhibition & MST(Days) \\
\hline PC & $17.60 \pm 2.54$ & 0.0 & $9.40 \pm 0.33$ \\
CQ & $3.19 \pm 0.01^{\mathrm{a}}$ & 81.9 & $31.61 \pm 2.72^{\mathrm{a}}$ \\
DX & $5.90 \pm 0.08^{\mathrm{b}}$ & 66.5 & $20.47 \pm 2.67^{\mathrm{b}}$ \\
D-P & $4.40 \pm 0.09^{\mathrm{a}}$ & 75.0 & $29.73 \pm 3.11^{\mathrm{a}}$ \\
D-P-DX & $0.86 \pm 0.07^{\mathrm{c}}$ & 95.1 & $37.12 \pm 3,29^{\mathrm{c}}$ \\
\hline
\end{tabular}

Data presented as \pm SEM, $n=5$, PC: Negative control, CQ: Chloroquine, DX: Doxycycline, D-P: Dihydroartemisinin-piperaquine, MST: Mean survival time. ${ }^{\mathrm{a}} \mathrm{p}<0.01,{ }^{\mathrm{b}} \mathrm{p}<0.05,{ }^{\mathrm{c}} \mathrm{p}<0.001$ Significant different when compared to PC, SEM: Standard error mean. 
Table 3. Prophylactic antiplasmodial effect of dihydroartemisinin-piperaquine-doxycycline on mice infected with Plasmodium berghei.

\begin{tabular}{llll}
\hline Treatment & \% Parasitemia & \% Inhibition & MST (Days) \\
\hline PC & $15.80 \pm 1.47$ & 0.0 & $9.79 \pm 0.22$ \\
CQ & $2.58 \pm 0.06^{\mathrm{a}}$ & 85.7 & $33.43 \pm 2.53^{\mathrm{a}}$ \\
DX & $5.51 \pm 0.07^{\mathrm{b}}$ & 65.1 & $22.75 \pm 3.57^{\mathrm{b}}$ \\
D-P & $3.03 \pm 0.04^{\mathrm{a}}$ & 86.8 & $30.91 \pm 2.89^{\mathrm{a}}$ \\
D-P-DX & $0.17 \pm 0.08^{\mathrm{c}}$ & 98.9 & $38.02 \pm 3.86^{\mathrm{c}}$ \\
\hline
\end{tabular}

Data presented as \pm SEM, $n=5$, PC: Negative control, CQ: Chloroquine, DX: Doxycycline, D-P: Dihydroartemisinin-piperaquine, MST: Mean survival time ${ }^{\mathrm{a}} \mathrm{p}<0.01,{ }^{\mathrm{b}} \mathrm{p}<0.05,{ }^{\mathrm{c}} \mathrm{p}<0.001$ Significant different when compared to PC, SEM: Standard error mean.

Table 4. Effect of dihydroartemisinin-piperaquine-doxycycline on hematologic parameters of mice infected Plasmodium berghei.

\begin{tabular}{lllll}
\hline Treatment & RBC $\left(\mathbf{x 1 0 ^ { 6 }}\right)$ & WBC $($ cells/L) & PCV $(\%)$ & Hb $(\mathbf{g} / \mathbf{d L})$ \\
\hline NC & $6.83 \pm 0.33$ & $7.55 \pm 0.09$ & $60.91 \pm 5.91$ & $16.93 \pm 1.35$ \\
PC & $3.21 \pm 0.43^{\mathrm{a}}$ & $15.71 \pm 1.55^{\mathrm{a}}$ & $26.72 \pm 3.45^{\mathrm{a}}$ & $6.01 \pm 0.17^{\mathrm{a}}$ \\
CQ & $5.44 \pm 0.28^{\mathrm{b}}$ & $9.44 \pm 0.19^{\mathrm{b}}$ & $44.21 \pm 4.33^{\mathrm{b}}$ & $13.45 \pm 1.38^{\mathrm{b}}$ \\
DX & $4.37 \pm 0.27^{\mathrm{c}}$ & $11.00 \pm 0.37^{\mathrm{c}}$ & $31.94 \pm 3.47^{\mathrm{c}}$ & $10.73 \pm 0.81^{\mathrm{c}}$ \\
D-P & $5.40 \pm 0.11^{\mathrm{b}}$ & $9.57 \pm 0.16^{\mathrm{b}}$ & $42.62 \pm 3.67^{\mathrm{b}}$ & $13.07 \pm 1.11^{\mathrm{b}}$ \\
D-P-DX & $6.61 \pm 0.32^{\mathrm{d}}$ & $7.25 \pm 0.01^{\mathrm{d}}$ & $55.9 \pm 4.41^{\mathrm{d}}$ & $16.72 \pm 1.37^{\mathrm{d}}$ \\
\hline
\end{tabular}

Data presented as \pm SEM, $n=5$, NC: Normal control, PC: Negative control, CQ: Chloroquine, DX: Doxycycline, D-P: Dihydroartemisinin-piperaquine, MST: Mean survival time, RBCs: Red blood cell, WBCs: White blood cell, PCV: Packed cell volume, Hb: Haemoglobin. ${ }^{\text {a }}$ p $<0.001$ significant difference when compared to NC, ${ }^{\mathrm{b}} \mathrm{p}<0.01,{ }^{\mathrm{c}} \mathrm{p}<0.05,{ }^{\mathrm{d}} \mathrm{p}<0.001$ Significant difference when compared to PC, SEM: Standard error mean.

Table 5. Effect of dihydroartemisinin-piperaquine on lipid parameters of mice infected with Plasmodium berghei.

\begin{tabular}{lllll}
\hline Group & TG $(\mathbf{m g} / \mathbf{d L})$ & TCHOL $(\mathbf{m g} / \mathbf{d L})$ & HDL-C $(\mathbf{m g} / \mathbf{d L})$ & LDL $(\mathbf{m g} / \mathbf{d L})$ \\
\hline NC & $80.8 \pm 7.03$ & $110.8 \pm 11.4$ & $50.4 \pm 4.00$ & $44.2 \pm 3.11$ \\
PC & $250.3 \pm 18.9^{\mathrm{a}}$ & $273.4 \pm 18.0^{\mathrm{a}}$ & $22.2 \pm 1.41^{\mathrm{a}}$ & $201.1 \pm 18 .^{\mathrm{a}}$ \\
CQ & $150.1 \pm 5.87^{\mathrm{b}}$ & $181.6 \pm 22.4^{\mathrm{b}}$ & $39.7 \pm 4.63^{\mathrm{b}}$ & $111.9 \pm 11.6^{\mathrm{b}}$ \\
DX & $200.7 \pm 3.03^{\mathrm{c}}$ & $220.0 \pm 12.0^{\mathrm{c}}$ & $30.6 \pm 4.22^{\mathrm{c}}$ & $149.3 \pm 15.0^{\mathrm{c}}$ \\
D-P & $159.0 \pm 4.87^{\mathrm{b}}$ & $170.7 \pm 13.5^{\mathrm{b}}$ & $38.7 \pm 4.00^{\mathrm{b}}$ & $100.2 \pm 12.5^{\mathrm{b}}$ \\
D-P-DX & $97.4 \pm 8.88^{\mathrm{d}}$ & $127.7 \pm 10.6^{\mathrm{d}}$ & $47.9 \pm 5.43^{\mathrm{d}}$ & $60.3 \pm 10.1^{\mathrm{d}}$ \\
\hline
\end{tabular}

Data presented as mean \pm SEM, $n=5$, NC: Normal control, PC: Negative control, CQ: Chloroquine, DX: Doxycycline, D-P: dihydroartemisininpiperaquine, TG: Tryglyceride, TCHOL: Total cholesterol, HDL: High density lipoproteins, LDL: Low density lipoprotein. ${ }^{a} \mathrm{p}<0.001$ Significant difference when compared to $\mathrm{NC},{ }^{\mathrm{b}} \mathrm{p}<0.01,{ }^{\mathrm{c}} \mathrm{p}<0.05,{ }^{\mathrm{d}} \mathrm{p}<0.001$ Significant difference when compared to PC, SEM: Standard error mean.

\section{DISCUSSION}

Malaria is a major health challenge in developing countries of sub-Saharan Africa and South East Asia. The emergence of widespread resistance of Plasmodium species to most antimalarial drugs, the increasing insecticide resistance by mosquitoes, and the lack of vaccines have made the fight against malaria seriously tasking (Beeson et al., 2016; Joseph et al., 2020). Hence there is an urgent need to discover alternative drugs with novel modes of action or a combination of currently existing antimalarial drugs to overcome these challenges. The present study, assessed whether antimalarial activity of D-P can be augmented by DX in mice infected with $P$. berghei. This study used invivo model, because it takes into cognizance the possible prodrug effect and the involvement of the immune system in eradicating malaria infection. $P$. berghei has been used in antiplasmodial studies in predicting experimental treatment outcomes and hence was appropriately used for the study (Satish et al., 2017). This study used suppressive test which determines the activity of a drug candidate on early infection and curative test, which evaluates the curative activity of a drug candidate on established infection (Mekonnen, 2015; Hiben et al., 2016). In the present study, in the curative test, D-P-DX decreased percentage parasitemia levels most when compared to individual doses of D-P, DX and CQ. The observed parasitemia inhibitions in the curative test were $64.9 \%, 71.1 \%, 93.6 \%$ in DX, D-P, and D-P-DX-treated mice, respectively. Also, in the suppressive and prophylactic tests, best decreases in percentage parasitemia levels occurred in D-P-DXtreated mice in comparison to individual doses of DX, D-P, and CQ. In the suppressive test, $66.5 \%, 75.0 \%$, and 95.1\%, parasitemia inhibitions were observed in DX, D$\mathrm{P}$, and D-P-DX treated mice respectively. In view of the antiplasmodial activity of D-P-DX observed in the 
present study, the ability of D-P-DX to prolong MST in mice was also evaluated. Treatment with D-P-DX prolonged MST in the curative, prophylactic and suppressive tests. The prolongation of MST by D-P-DX was best when compared to individual doses of DX, D$\mathrm{P}$, and CQ. Hematological abnormalities like anemia caused by erythrocyte destruction are common characteristics of $P$. berghei-infected mice. Rodent malaria causes parasite-induced decrease in PCV, which occurs approximately $48 \mathrm{~h}$ post-infection (Nardos and Makonnen, 2017). In the present study, notable signs of anemia marked by low levels of HB, PCV RBCs and increased WBCs levels were observed in P. bergheiinfected mice. However, P. berghei- induced anemia was curtailed in D-P-DX treated mice when compared to individual doses of DX, D-P, and CQ. Studies have reported that changes in serum lipids could be possible features of malaria (Visser et al., 2013). The present study observed elevated TCHOL, TG, and LDL-C and decreased HDL-C levels in $P$. berghei-infected mice. However, D-P-DX restored serum lipid characterized by decreased TCHOL, TG, LDL-C and increased HDL-C levels. The observed antiplasmodial effect of D-P-DX may be due to different modes of antiplasmodial activity of the partner drugs. Dihydroartemisinin acts through the cleavage of the endoperoxide bridge and the production of free radicals (Meshnick, 1994). Piperaquine is suggested to have similar mode of action as CQ (Meshnick, 1994). In parasite food vacuole, concentrated CQ binds free hematin forming CQhematin complex. This interferes with enzymatic processes in the parasite causing parasite death (Tärning et al., 2007). The antiplasmodial mode of action of DX is not clear, but studies suggested the inhibition of mitochondrial protein, nucleotides and deoxynucleotides syntheses in Plasmodium (Yeo et al., 1997; Prapunwattana et al., 1998).

\section{CONCLUSION}

This study showed that D-P-DX produced the best antiplasmodial activity in $P$. berghei-infected mice when compared to individual doses of D-P, DX and CQ. Also, alterations in lipid profile and hematological parameters were best restored by D-P-DX when compared to individual doses of D-P, DX and CQ. This shows that D-P-DX may be an effective antimalarial drug combination.

Acknowledgement: The authors appreciate the Laboratory staff of the Department of Pharmacology, Faculty of Basic Clinical Sciences, University of Port Harcourt, Nigeria.

Conflict of interest: The authors declare no conflicts of interest.

Financial disclosure: None

\section{REFERENCES}

Amaratunga C, Lim P, Suon S, Sreng, S, Mao S, Sopha C et al. (2016). Dihydroartemisinin-piperaquine resistance in Plasmodium falciparum malaria in Cambodia: A multisite prospective cohort study. Lancet Infect Dis. 16, 357.

Amato D.R, Lim P, Miotto O, Amaratunga C, Dek D, Pearson R.D et al. (2017) Genetic markers associated with dihydroartemisinin-piperaquine failure in Plasmodium falciparum malaria in Cambodia: A genotype-phenotype association study. Lancet Infect Dis. 17, 164-173

Basco, L K, \& Le Bras J. (1993). Activity in vitro of doxycycline against multidrug-resistant Plasmodium falciparum. Transaction of Royal Society of Tropical Medicine and Hygiene. 87:469-470

Beeson JG, Drew DR, Boyle MJ, Feng G, Fowkes FJ, Richards JS et al. (2016) Merozoite surface proteins in red blood cell invasion, immunity and vaccines against malaria. FEMS Microbiology Review. 40(3):343-372.

Desai M, Hill J, Fernandes S, Walker P, Pell C, Gutman J et al. (2018). Prevention of malaria in pregnancy. Lancet Infectious Disease. 18, 119-132.

Gaillard T, Madamet M, \& Pradines B. (2015). Tetracyclines in malaria. Malarial Journal. 14, $445 ; 1-10$.

Griffith KS, Lewis LS, Mali S, \& Parise ME. (2007) Treatment of malaria in the United States: a systematic review. Journal of American Medical Association. 297:2264-2277

Hiben MG, Sibhat GG, Fanta BS, Gebrezgi HD, \& Tesema SB (2016). Evaluation of Senna singueana leaf extract as an alternative or adjuvant therapy for malaria. Journal of Traditional and Complimentary Medicine. 6:112-117

Joseph AO, \& Samson OT (2020) Antiplasmodial Efficacy of Anacardium occidentale in Albino Mice Infected with Plasmodium berghei. Journal of Family Medicine and Disease Prevention. 6:123;1-6

Kakuru A, Jagannathan P, Muhindo M.K, Natureeba P, Awori, P, Nakalembe M, et al., (2016) Dihydroartemisinin-Piperaquine for the Prevention of Malaria in Pregnancy. New England Journal of Medicine. 374, 928-939.

Knight DJ, \& Peters W. (1980). The antimalarial action of $\mathrm{N}$ Benzyl oxydihydrotriazines and the studies on its mode of action. Annals of Tropical Medicine and Parasitology. 74: 393-404.

Leang R, Barrette A, Bouth DM, Menard D, Abdur R, Duong S et al., (2013). Efficacy of dihydroartemisinin-piperaquine for treatment of uncomplicated Plasmodium falciparum and Plasmodium vivax in Cambodia, 2008 to 2010. Antimicrobial Agents Chemotherapy. 57, 818-826.

McEvoy G. (2008). AHFS Drug Information. Bethesda, MD American Society of Health-System Pharmacists, Inc; 2008.

Mekonnen LB. (2015). In vivo antimalarial activity of the crude root and fruit extracts of Croton macrostachyus (Euphorbiaceae) against Plasmodium berghei in mice. Journal of Traditional and Complimentary Medicine. 5:168e173

Meshnick SR. (1994) The mode of action of antimalarial endoperoxides. Transaction of Royal Society of Tropical Medicine and Hygiene 88:131-2.

Nardos A, \& Makonnen E (2017). In vivo antiplasmodial activity and toxicological assessment of hydroethanolic crude extract of Ajuga remota. Malarial Journal. 16:25; 1-8

Nosten F, \& White NJ. (2007) Artemisinin-based combination treatment of falciparum malaria. American Journal of Tropical Medicine and Hygiene. 77, 181-192 
Peters W. (1967). Rational methods in the search for antimalarial drugs. Transaction of Royal Society of Tropical Medicine and Hygiene. 61: 400-410.

Prapunwattana P, O’Sullivan WJ, \& Yuthavong Y. (1988). Depression of Plasmodium falciparum dihydroorotate dehydrogenase activity in in vitroculture by tetracycline. Molecular and Biochemical Parasitology. 27:119-24.

Ryley JF, \& Peters W. (1970) The antimalarial activity of some quinolone esters. Annals of Tropical Medicine and Parasitology. 84: 209-222.

Satish PVV, Kumari DS, \& Sunita K, (2017) Antiplasmodial efficacy of Calotropis gigantean (L.) against Plasmodium falciparum (3D7 strain) and Plasmodium berghei (ANKA). Journal of Vector Borne Disease. 54(3):215-225

Saunders D. L, Vanachayangkul P, \& Lon C. (2014) Dihydroartemisinin-Piperaquine Failure in Cambodia. New England Journal of Medicine. 371, 484-485

Somsak V, Damkaew A, \& Onrak P. (2018) Antimalarial activity of kaempferol and its combination with chloroquine in Plasmodium berghei infection in mice. Journal of Pathology. 2018:1-7.

Tan KR, Magill AJ, Parise ME, \& Arguin PM, (2011). Doxycycline for Malaria Chemoprophylaxis and Treatment: Report from the CDC Expert Meeting on Malaria Chemoprophylaxis, Hygiene. 5; 84(4): 517-531.
Tärning J. Piperaquine, Bioanalysis (2007) Drug Metabolism and Pharmacokinetics. Göteborg, Sweden: Institute of Neuroscience and Physiology, Department of Pharmacology, The Sahlgrenska Academy at Göteborg University

Tayler NM, De Jesús R, Spadafora R, Coronado LM, R, \& Spadafora C (2020) Antiplasmodial activity of Cocos nucifera leaves in Plasmodium berghei-infected mice. Journal of Parasitic Disease 44, 305-313.

Visser BJ, Wieten RW, Nagel IM. \& Grobusch MP (2013) Serum lipids and lipoproteins in malaria - a systematic review and meta-analysis. Malarail Journal. 12, 442, 1-16

WHO. World Malaria Report 2016. Geneva: World Health Organization; 2016

Yavo W, Faye B, Kuete T, Djohan V, Oga SA, Kassi RR et al. (2011). Multicentric assessment of the efficacy and tolerability of dihydroartemisinin-piperaquine compared to artemether-lumefantrine in the treatment of uncomplicated Plasmodium falciparum malaria in Sub-Saharan Africa. Malarial Journal. 2011; 10:198.

Yeo AE, Edstein MD, Shanks GD, \& Rieckmann KH (1997). Potentiation of the antimalarial activity of atovaquone by doxycycline against Plasmodium falciparum in vitro. Parasitology Research. 83:489-91. 